\title{
The influence of socio-demographic factors on the nutritional status of children in the Stellenbosch area, Western Cape
}

Kirsten AP, MSc, Clinical Dietitian, Division of Human Nutrition, Stellenbosch University Marais D, PhD, Senior Teaching Fellow, Division of Applied Health Sciences, University of Aberdeen Schübl C, BNutrition, Assistant Director, Division of Human Nutrition, Faculty of Medicine and Health Sciences, Tygerberg Academic Hospital; and Stellenbosch University Correspondence to: Anél Kirsten, email: anelkirsten@yahoo.com Keywords: nutritional intake, socio-demographic, obesity, children, overweight

\section{Abstract}

Objectives: To determine the prevalence of overweight and obesity, as well as socio-demographic risk factors associated with childhood overweight and obesity in the Stellenbosch area, Western Cape province.

Design: A cross-sectional, comparison study was conducted.

Setting and subjects: A representative group of 638 children (aged 6-13 years) attending three randomly selected Stellenbosch primary schools. An additional school was selected for the pilot study. In the screening (first) phase, children were weighed and measured to calculate body mass index using international obesity task force guidelines to determine the prevalence of overweight and obesity. For the comparison (second) phase of the study, only 24 overweight and obese children and 21 children of normal weight (comparison group) $(n=45)$ were included.

Outcome measures: Socio-demographic and eating behaviour data were collected using a structured questionnaire and compared between the overweight and obese group and the comparison group (normal weight) to identify associated risk factors.

Results: The prevalence of overweight and obesity was $13 \%$, of which $9 \%(n=57)$ were overweight and $4 \%(n=27)$ obese in the screening phase. In the comparison phase, socio-economic factors, such as maternal employment hours ( $p$-value $=0.0462$ ); family characteristics, such as the number of children in the household ( $p$-value $=0.0231$ ); and time spent participating in sport ( $p$-value $=0.0450$ ); were significantly associated with overweight or obesity.

Conclusion: Preventative initiatives should proactively promote healthy eating behaviour and physical activity in children at an early age, based on previous research, particularly in girls. Involving families and schools in these initiatives is recommended, as well as a national childhood obesity monitoring system to identify children at risk, and tracking childhood obesity trends to guide evidence-based interventions to tackle this growing public health issue.

(P) Peer reviewed. (Submitted: 2012-09-25. Accepted: 2013-05-12.) ๑ SAJCN

S Afr J Clin Nutr 2013;26(3):124-131

\section{Introduction}

Obesity has rapidly become one of the most important medical and public health problems of our times. The worldwide increase in the prevalence of childhood overweight and obesity ${ }^{1-3}$ has been identified as a major threat to children's health and South Africa has not been spared. ${ }^{4}$ Obesity's role as a health risk in adults has been well-recognised for some time, but in the past little attention was paid to obesity in childhood. ${ }^{5}$

South Africa is no different from other developing countries that are facing the double burden of both infectious and chronic (noncommunicable) diseases, with an increasing prevalence of overweight and obesity in children and adults. To date, most studies in South Africa have tended to focus on childhood undernutrition, especially stunting, since it is regarded as one of the major health problems in the country and receives considerable attention in terms of policy and intervention strategies. ${ }^{4}$ However, secondary analysis of the National Food Consumption Survey (NFCS) conducted in 1999 in South Africa, ${ }^{6,7}$ suggests that overweight and obesity outweigh the problem of stunting. It has been noted that South African primary schoolchildren are showing similar trends of obesity and overweight to those in developed countries approximately 10 years ago. ${ }^{4}$ The World Health Organization recommends that developing countries monitor these trends, particularly the co-existence of stunting and overweight in children, since these are risk factors for diseases of lifestyle in adulthood. ${ }^{8,9}$ 
The aetiology of overweight and obesity is complex and multifactorial. Various social, biological and environmental determinants of obesity have been investigated. ${ }^{5}$ Intrauterine life, infancy, and the preschool period [around the time of the adiposity or body mass index (BMI) rebound] have all been considered to be possible critical periods during which the long-term regulation of energy balance may be programmed and which can relate to later risk of obesity. ${ }^{8,10,11}$ The epidemiology of overweight and obesity strongly suggests that environmental determinants, particularly those found within families, are significant in both the aetiology and treatment of childhood obesity. ${ }^{12-14}$

Socio-economic status, parents' education and jobs, family size, parental weight, number of obese family members, marital status, parental style, intra-familial relationships, communication and support, as well as eating and activity patterns, have all been shown to play an important potential role in the aetiology of obesity. ${ }^{13,14}$ The role of parental eating habits and that of the home and broader social environment has been recognised, but few studies have focused on the impact of this on childhood obesity. ${ }^{3}$ There is an increasing body of evidence that the early-life environment is an important determinant of risk of obesity in later life. ${ }^{8}$

Obesity in childhood has serious medical and psychological consequences which continue into adulthood. Therefore, it is important to establish healthy eating patterns early in life, particularly in the first five years. This is the period in which children acquire many of their physical attributes and habits. ${ }^{15}$

Therefore, this study aimed to determine the prevalence of overweight and obesity in children in the Stellenbosch area, Western Cape province, and provide evidence of a possible association between the home environment, and socio-economic factors and the risk of overweight and obesity.

\section{Method}

A cross-sectional, comparison study was conducted in two phases, i.e. a screening phase and the group comparison study phase. The study population consisted of a representative group of children, aged 6-13 years from both sexes, attending three randomly selected Stellenbosch primary schools. Stellenbosch primary schools were stratified into three strata, i.e. high $(n=4)$, medium $(n=6)$ and low $(n=9)$ socio-economic status (SES) groups, based on annual school fees paid as a proxy for SES. Two schools from each SES group were selected by using random number tables and a random starting point to provide a socio-demographic representative study population. One additional school from the lower SES group was randomly selected for the pilot study.

The first phase of research involved screening the children to establish their anthropometric status to enable the prevalence of overweight and obesity to be determined. Children gave verbal assent to being weighed and measured. (Parental consent was not required for the initial screening phase). Standard procedures previously used in studies by Jerusa et al and Steyn et al were used to calculate BMI and nutritional status was classified using International Association for the Study of Obesity (IASO/IOTF) guidelines. ${ }^{6,10}$
The second phase of the research followed a cross-sectional comparison design. Children who had been classified as overweight or obese comprised the overweight and obese group, and individuals with a BMI below the cut-off points (normal weight), paired for sex and age (within one year of age category), were assigned to the comparison group.

The parents of the selected children were provided with a questionnaire which was used to determine the SES, eating behaviour, family characteristics and food consumption of the overweight and obese group and the paired comparison group. Parents were provided with the opportunity to waive consent for their child to participate by not completing the questionnaire. The questionnaire was available in English and Afrikaans and included four sections, i.e. socio-demographic and family characteristics, eating habits, lifestyle and a semi-quantitative food frequency questionnaire (FFQ). Collected socio-demographic data included information on SES, parental employment and education, household income, marital status, maternal age and household composition. The eating habits section included questions on the amount of money spent each week on food, if meals were eaten together, and where meals were consumed, as well as infant-feeding practices. The lifestyle section included questions on activity levels (rated from $0-10$ ), and hours spent as "screen time", i.e. watching television and computer or games usage.

During the pilot study, the 1999 NFCS FFQ ${ }^{6}$ was shortened and simplified for the purposes of this study and face validated at the seventh randomly selected primary school that was then excluded from the final study population.

An information session was offered at the participating schools to address any questions and assist parents with completion of the questionnaires. However, participating schools felt that this was not necessary and unpractical. Therefore, contact details were made available for parents to contact the researcher.

Descriptive statistics were used to discuss the objectives of the study by means of Microsoft Exce ${ }^{\circledR}$ spreadsheets. Data were captured electronically and controlled for precision of data transfer with regular cross-referencing. Data were analysed by the Centre for Statistical Consultation using StatSoft Statistica ${ }^{\circledR}$ data analysis software system version 10. Missing data were excluded per variable.

Ethics approval was obtained from the Health Research Ethics Committee, Faculty of Health Sciences, Stellenbosch University (Ref No. N08/08/232). Permission to perform the research was obtained from the Western Cape Education Department, as well as individual primary schools in the Stellenbosch area that were willing to participate.

\section{Results}

\section{First phase}

A total of 638 children were weighed and measured during the anthropometrical screening phase. The prevalence of overweight and obesity in this sample of primary school children was $13 \%$ 
$(\mathrm{n}=84)$, of which $9 \%(\mathrm{n}=57)$ were classified as overweight and $4 \%(n=27)$ as obese. The prevalence of overweight and obesity was highest in girls (63\%), in children aged $9-12$ years (17\%), and in higher SES areas (42\%). No significant association was found between nutritional status and SES ( $p$-value $=0.2998$, chi-square test), sex ( $p$-value $=0.9862$, chi-square test) or age ( $p$-value $=$ 0.7390, Mann-Whitney U test)

\section{Second phase}

In this comparison phase of the study, 168 questionnaires, 84 in the overweight or obese group and 84 in the comparison group, were sent to caregivers of the selected children. There was a very poor response rate of $27 \%(n=45)$, which included $24(53 \%)$ of overweight and obese children and 21 (46\%) children in the comparison group. The largest proportion $(49 \%, n=22)$ of respondents were in the medium SES group. The distribution of anthropometric status of the respondents was $20 \%(n=9)$ obese, $33 \%(n=15)$ overweight and $47 \%(n=21)$ normal weight. There was no association between anthropometric status and sex ( $p$-value $=0.3886$, Mann-Whitney $\mathrm{U}$ test) or age ( $\mathrm{p}$-value $=0.2622$, Spearman rank correlation coefficients).

Table I has limitations as not all of the questions in the questionnaire were answered by the total study population, and because of the missing data, there is a difference in the " $n$ " totals. The majority of the children $(67 \%, n=8)$ in the high SES group $(n=12)$ had a normal weight, and more than half of the children $(73 \%, n=8)$ in the low SES group ( $n=11$ ) were overweight and obese, indicating a trend that the lower the SES, the more likely the children were to be overweight or obese. Overweight and obesity were more prevalent in children from households in the middle income group (R11 000-R20 000), where both parents or caregivers earned an income, and in households with R400-R500 weekly food expenditure, and where mothers, as well as fathers, had a low education level. Although differences were noted, most of the SES indicators were not significantly associated with anthropometric status and only indicated trends (Table I). However, participants whose mothers worked for more than 36 hours a week were statistically significantly more overweight or obese ( $p$-value $=$ $0.0462, \mathrm{M}-\mathrm{L}$ chi-square test).

There was no significant association between family characteristics and anthropometric status (Table II), except in households with two children, where there was a statistically significant positive association with overweight and obesity $(p$-value $=0.0231$, Spearman rank correlation coefficients).

Eighty-four per cent $(n=38)$ of the total number of children $(n=45)$ were breastfed. The distribution was very similar in the overweight and obese group $(32 \%, n=12)$ and the comparison group (30\%, $\mathrm{n}=11$ ). A trend was not observed that might have suggested that breastfeeding was a protective factor against childhood overweight or obesity. Although trends were noted regarding eating patterns, no factors indicated a statistically significant association between anthropometrical status and family eating habits (Table III).
Table I: Anthropometric status in relation to indicators of the socioeconomic status of households in the comparison study phase of primary children in the Stellenbosch area, Western Cape

\begin{tabular}{|c|c|c|c|c|}
\hline Indicators & $\mathbf{n}$ & p-value & $\begin{array}{c}\text { Comparison } \\
\text { group }\end{array}$ & $\begin{array}{l}\text { Overweight and } \\
\text { obese group }\end{array}$ \\
\hline Household income & \multirow{4}{*}{38} & \multirow{4}{*}{ *0.0198 } & 19 & 19 \\
\hline$<\mathrm{R} 1$ 000-R5 000 & & & $8(42 \%)$ & $7(37 \%)$ \\
\hline R6 000-R20 000 & & & $5(26 \%)$ & $9(48 \%)$ \\
\hline $\mathrm{R} 20$ 000-> R51 000 & & & $6(32 \%)$ & $3(15 \%)$ \\
\hline Sources of income & \multirow{5}{*}{45} & \multirow{5}{*}{${ }^{*} 0.1436$} & 21 & 24 \\
\hline One person & & & $9(43 \%)$ & $3(13 \%)$ \\
\hline $\begin{array}{l}\text { Both parents or } \\
\text { caregivers }\end{array}$ & & & $10(48 \%)$ & $19(79 \%)$ \\
\hline Grants & & & $2(10 \%)$ & $1(4 \%)$ \\
\hline Family & & & 0 & $1(4 \%)$ \\
\hline $\begin{array}{l}\text { Weekly food } \\
\text { expenditure }\end{array}$ & \multirow{4}{*}{44} & \multirow{4}{*}{${ }^{*} 0.1204$} & 20 & 21 \\
\hline$<$ R100-R300 & & & $3(15 \%)$ & $1(4 \%)$ \\
\hline R300-R500 & & & $9(45 \%)$ & $16(66 \%)$ \\
\hline$>\mathrm{R} 500$ & & & $8(40 \%)$ & $7(29 \%)$ \\
\hline Paternal employment & \multirow{5}{*}{41} & \multirow{5}{*}{${ }^{*} 0.0833$} & 20 & 21 \\
\hline Employed & & & $4(20 \%)$ & $1(4.8 \%)$ \\
\hline Self-employed & & & $8(40 \%)$ & $4(19 \%)$ \\
\hline Wage earner & & & $8(40 \%)$ & $16(76.2 \%)$ \\
\hline Retired by choice & & & 0 & 0 \\
\hline Maternal employment & \multirow{5}{*}{37} & \multirow{5}{*}{${ }^{*} 0.0462$} & 15 & 22 \\
\hline$<16$ hours/week & & & $5(33 \%)$ & $4(18 \%)$ \\
\hline 16-36 hours/week & & & $5(33 \%)$ & $2(9 \%)$ \\
\hline 36-40 hours/week & & & $3(20 \%)$ & $8(36 \%)$ \\
\hline$>40$ hours/week & & & $2(13 \%)$ & $8(36 \%)$ \\
\hline Maternal education & \multirow{8}{*}{45} & \multirow{8}{*}{${ }^{* *} 0.9516$} & 21 & 24 \\
\hline None & & & 0 & 0 \\
\hline Primary school & & & $1(5 \%)$ & $1(4 \%)$ \\
\hline Grade $8-10$ & & & $3(14 \%)$ & $6(25 \%)$ \\
\hline Grade 11-12 & & & $8(38 \%)$ & $8(33 \%)$ \\
\hline College & & & $4(19 \%)$ & $2(8 \%)$ \\
\hline University & & & $5(24 \%)$ & $6(25 \%)$ \\
\hline Technicon & & & 0 & $1(4 \%)$ \\
\hline Paternal education & \multirow{8}{*}{43} & \multirow{8}{*}{ "0.9097 } & 20 & 23 \\
\hline None & & & $1(5 \%)$ & 0 \\
\hline Primary school & & & 0 & 0 \\
\hline Grade $8-10$ & & & $4(20 \%)$ & $6(26 \%)$ \\
\hline Grade 11-12 & & & $5(25 \%)$ & $9(39 \%)$ \\
\hline College & & & $3(15 \%)$ & $3(13 \%)$ \\
\hline University & & & $7(35 \%)$ & $5(22 \%)$ \\
\hline Technicon & & & 0 & 0 \\
\hline
\end{tabular}


Table II: Anthropometric status in relation to indicators of family characteristics in the comparison study phase of primary school children in the Stellenbosch area, Western Cape

\begin{tabular}{|c|c|c|c|c|}
\hline Indicators & $\mathbf{n}$ & p-value & $\begin{array}{l}\text { Comparison } \\
\text { group }\end{array}$ & $\begin{array}{l}\text { Overweight and } \\
\text { obese } \\
\text { group }\end{array}$ \\
\hline Mothers age (years) & \multirow{8}{*}{45} & \multirow{8}{*}{${ }^{*} 0.8668$} & 21 & 24 \\
\hline$<16$ & & & $2(10 \%)$ & $1(4 \%)$ \\
\hline $16-18$ & & & 0 & 0 \\
\hline $18-20$ & & & 0 & 0 \\
\hline $20-25$ & & & $1(5 \%)$ & 0 \\
\hline $25-30$ & & & $2(10 \%)$ & $1(4 \%)$ \\
\hline $35-40$ & & & $10(48 \%)$ & $18(75 \%)$ \\
\hline$>40$ & & & $6(29 \%)$ & $4(17 \%)$ \\
\hline Marital circumstances & \multirow{8}{*}{45} & \multirow{8}{*}{${ }^{\prime *} 0.2851$} & 21 & 24 \\
\hline Married & & & $14(67 \%)$ & $21(88 \%)$ \\
\hline $\begin{array}{l}\text { Divorced or living } \\
\text { alone }\end{array}$ & & & $3(14 \%)$ & 0 \\
\hline Single or living alone & & & 0 & 0 \\
\hline Living with a partner & & & $2(10 \%)$ & 0 \\
\hline $\begin{array}{l}\text { Separated or living } \\
\text { alone }\end{array}$ & & & $1(5 \%)$ & $1(4 \%)$ \\
\hline Widowed & & & $1(5 \%)$ & $1(4 \%)$ \\
\hline $\begin{array}{l}\text { Single or living with } \\
\text { family }\end{array}$ & & & 0 & $1(4 \%)$ \\
\hline Household number & \multirow{5}{*}{45} & \multirow{5}{*}{ ‘0.7727 } & 21 & 24 \\
\hline 1-3 person & & & $5(24 \%)$ & $6(25 \%)$ \\
\hline 4-6 persons & & & $15(71 \%)$ & $16(67 \%)$ \\
\hline 7-10 persons & & & $1(5 \%)$ & $2(8 \%)$ \\
\hline$>10$ persons & & & 0 & 0 \\
\hline Children in household & \multirow{5}{*}{45} & \multirow{5}{*}{0.0231} & 21 & 24 \\
\hline 1 child & & & $3(14 \%)$ & $5(21 \%)$ \\
\hline 2 children & & & $7(33 \%)$ & $14(58 \%)$ \\
\hline 3 children & & & $9(43 \%)$ & $5(21 \%)$ \\
\hline 4 children & & & $2(10 \%)$ & 0 \\
\hline
\end{tabular}

A very limited number of questionnaires were returned. From the 45 received responses, a usual food intake, obtained using a FFQ, indicated a statistically significant association with anthropometric status for the intake of pork ( $p$-value $=0.0143$ ), brown rice $(p$-value $=0.0371)$, canola or olive margarine $(p$-value $=0.0398)$, polyunsaturated margarine $(p$-value $=0.0481)$ and doughnuts $(p$-value $=0.0280)$ (Kruskal-Wallis test). Therefore, it seems that an increased frequency of intake of brown rice showed an association with normal weight. The more frequently pork, canola or olive or
Table III: Anthropometric status according to indicators of dietary patterns in the comparison study phase of primary school children in the Stellenbosch area, Western Cape

\begin{tabular}{|c|c|c|c|c|}
\hline Indicators & n & p-value & $\begin{array}{l}\text { Comparison } \\
\text { group }\end{array}$ & $\begin{array}{l}\text { Overweight and } \\
\text { obese group }\end{array}$ \\
\hline Set meals & \multirow{3}{*}{44} & \multirow{3}{*}{${ }^{*} 0.0511$} & 20 & 24 \\
\hline Yes (\%) & & & 17 (85\%) & $13(54 \%)$ \\
\hline № (\%) & & & $3(15 \%)$ & $11(46 \%)$ \\
\hline Meals eaten together & \multirow{5}{*}{44} & \multirow{5}{*}{${ }^{*} 0.2215$} & 20 & 24 \\
\hline 1-2/week & & & $3(15 \%)$ & $3(13 \%)$ \\
\hline 3-4/week & & & $3(15 \%)$ & $4(17 \%)$ \\
\hline 5-6/week & & & $4(20 \%)$ & $5(21 \%)$ \\
\hline 7/week & & & $10(50 \%)$ & $12(50 \%)$ \\
\hline Where eaten & \multirow{4}{*}{41} & \multirow{4}{*}{ *0.9538 } & 20 & 24 \\
\hline $\begin{array}{l}\text { In front of the } \\
\text { television }\end{array}$ & & & $9(45 \%)$ & $12(50 \%)$ \\
\hline Dining area & & & $6(30 \%)$ & $5(21 \%)$ \\
\hline Kitchen & & & $5(25 \%)$ & $7(29 \%)$ \\
\hline Food preparation & \multirow{5}{*}{44} & \multirow{5}{*}{ *0.5242 } & 20 & 24 \\
\hline Mother & & & $14(70 \%)$ & $16(67 \%)$ \\
\hline Father & & & 0 & $2(8 \%)$ \\
\hline Both & & & $3(15 \%)$ & $4(17 \%)$ \\
\hline Family member & & & $3(15 \%)$ & $2(8 \%)$ \\
\hline
\end{tabular}

*: p-value calculated according to the chi-square test

polyunsaturated margarine and/or doughnuts were consumed, the higher the likelihood of overweight and obesity.

Exercise habits were explored and a trend was observed that overweight and obesity risk increased as screen time increased (Table IV). The mean value for activity perception by parents $(\mathrm{n}=$ 43) was seven on a scale of 1-10 (10 indicating very active). As the perception of activity levels increased, so did the presence of normal weight, although no statistically significant association was seen. The majority of the group who didn't participate in sport were more prone to being overweight $(38 \%)$. Children who spent less than one hour a day participating in sport were more likely to be overweight and obese, while those who spent 1-2 hours a day involved in sport showed a positive association with the prevention of obesity and overweight.

\section{Discussion}

This Stellenbosch-based study found a lower prevalence rate [13\% in $6-13$ year-old children ( $9 \%$ overweight and $4 \%$ obese)] than the estimated childhood international prevalence of $25 \%$, including overweight (14\%) and obesity (11\%) for children between the ages of 6-17 years. ${ }^{16}$ More recent global research conducted between 2000-2007 on the prevalence of childhood overweight and obesity $\left(\right.$ Table V) ${ }^{4,17-28}$ indicates a higher prevalence than earlier international studies and the current estimation of $25 \%$. 
Table IV: Anthropometric status according to indicators of activity levels in the comparison study phase of primary children in the Stellenbosch area, Western Cape

\begin{tabular}{|c|c|c|c|c|}
\hline Indicators & $\mathbf{n}$ & p-value & $\begin{array}{c}\text { Comparison } \\
\text { group }\end{array}$ & $\begin{array}{l}\text { Overweight and } \\
\text { obese group }\end{array}$ \\
\hline Screen time during the week & \multirow{4}{*}{44} & \multirow{4}{*}{${ }^{*} 0.1185$} & 20 & 24 \\
\hline$<1$ hour/day and $\geq 1$ hours/day & & & $11(55 \%)$ & $11(46 \%)$ \\
\hline$<3$ hours/day and $\geq 4$ hours/day & & & $7(35 \%)$ & $10(42 \%)$ \\
\hline$\geq 5$ hours/day & & & $2(10 \%)$ & $3(12 \%)$ \\
\hline Screen time during the weekend & \multirow{4}{*}{44} & \multirow{4}{*}{${ }^{*} 0.3593$} & 20 & 24 \\
\hline$<1$ hour/day and $\geq 1$ hours/day & & & $10(50 \%)$ & $5(21 \%)$ \\
\hline$<3$ hours/day and $\geq 4$ hours/day & & & $7(35 \%)$ & $14(58 \%)$ \\
\hline$\geq 5$ hours/day & & & $3(15 \%)$ & $5(21 \%)$ \\
\hline Activity perception & \multirow{11}{*}{43} & \multirow{11}{*}{ *0.1089 } & 19 & 24 \\
\hline 1 & & & 0 & 0 \\
\hline 2 & & & $1(5 \%)$ & 0 \\
\hline 3 & & & 0 & $2(8 \%)$ \\
\hline 4 & & & 0 & $1(4 \%)$ \\
\hline 5 & & & $3(16 \%)$ & $4(17 \%)$ \\
\hline 6 & & & $1(5 \%)$ & $4(17 \%)$ \\
\hline 7 & & & $1(5 \%)$ & $6(25 \%)$ \\
\hline 8 & & & $6(32 \%)$ & $4(17 \%)$ \\
\hline 9 & & & $3(16 \%)$ & 0 \\
\hline 10 & & & $4(21 \%)$ & $3(13 \%)$ \\
\hline Participation in sport & \multirow{3}{*}{44} & \multirow{3}{*}{${ }^{*} 0.2438$} & 20 & 24 \\
\hline Yes & & & $13(65 \%)$ & $10(42 \%)$ \\
\hline No & & & $7(35 \%)$ & $14(58 \%)$ \\
\hline Time spent doing sport & \multirow{4}{*}{43} & \multirow{4}{*}{${ }^{*} 0.0450$} & 20 & 23 \\
\hline$<1$ hour/day and $\geq 1$ hours/day & & & $18(90 \%)$ & $22(96 \%)$ \\
\hline$<3$ hours/day and $\geq 4$ hours/day & & & $2(10 \%)$ & $1(4 \%)$ \\
\hline$\geq 5$ hours/day & & & 0 & 0 \\
\hline
\end{tabular}

From a South African point of view, the overweight and obesity prevalence in Stellenbosch (13\%) was lower than that in previous national studies, such as the 1999 NFCS $(17 \%)^{6}$ and the 2001-2004 Health of the Nation Study (35.6\%), ${ }^{4}$ but was higher when compared to the 1999 prevalence data relating to the Western Cape $(5 \%) .{ }^{6}$ The Western Cape and Stellenbosch prevalence data were lower than those in the 1999 NFCS findings, as community study prevalence data are expected to be less than that of the national averages. The 2004 Health of the Nation study showed a trend of obesity and overweight in South African children that was similar to values in developed countries approximately 10 years ago. ${ }^{4}$ The co-existence of an increasing prevalence of overweight, with persistent moderate stunting and wasting at a lower level, poses unique challenges in the African and global context. $^{9}$

This study found higher prevalence rates of overweight and obesity in girls (8\%), which is supported by international datasets from Australia (24\%), ${ }^{18}$ England (26.6\%), ${ }^{22}$ Mexico $(29 \%),{ }^{24}$ Sweden $(19.5 \%),{ }^{25}$ the USA $(36 \%),{ }^{28}$ Philippines $^{29}$ and a 2002 study conducted by the IASO/IOTF in conjunction with the European Childhood Obesity Group. ${ }^{17}$

A higher prevalence of overweight and obesity was noted among the older children. The most prevalent were the 9-year-old children (17\%) and the 12-year-old children (17\%). These results correlate well with the findings of other international research. ${ }^{30}$ By contrast, the 1999 South African NFCS found the highest prevalence of overweight in children aged 1-3 years. ${ }^{6}$ However, another South African study, conducted in 1999, found children, and in particular girls, to be more prone to obesity and overweight. This occurred prior to the growth spurt at 10 years, as well as after menarch. ${ }^{31}$ The increased prevalence in these age groups is perhaps

Table V: Comparison of global percentage prevalence rates of childhood overweight and obesity using International Association for the Study of Obesity (IASO/ IOTF) cut-off points ${ }^{4,17-28}$

\begin{tabular}{|c|c|c|c|c|c|c|c|c|c|}
\hline \multirow[t]{2}{*}{ Country } & \multirow[t]{2}{*}{ Year of survey } & \multirow[t]{2}{*}{ Age range (years) } & \multirow{2}{*}{$\begin{array}{l}\% \text { OW } \\
\text { and } 0\end{array}$} & \multicolumn{3}{|c|}{ Boys } & \multicolumn{3}{|c|}{ Girls } \\
\hline & & & & OW & 0 & Total & OW & 0 & Total \\
\hline Australia $^{18}$ & 2007 & $2-16$ & 46 & 17 & 5 & 22 & 18 & 6 & 24 \\
\hline Brazil ${ }^{19}$ & 2002 & $7-10$ & 44 & 17.1 & 6 & 23 & 16.1 & 5 & 21 \\
\hline Chile $e^{20}$ & 2002 & 6 & 55.6 & 18.8 & 9.8 & 28.6 & 19.6 & 7.5 & 27 \\
\hline China $^{21}$ & 2002 & $7-17$ & 10.4 & 4.8 & 1.1 & 5.9 & 3.9 & 0.6 & 4.5 \\
\hline England $d^{22}$ & 2007 & $5-17$ & 49.3 & 17 & 5.7 & 22.7 & 19.6 & 7 & 26.6 \\
\hline $\mathrm{Japan}^{23}$ & $1996-2000$ & $6-14$ & 30.6 & 12.4 & 3.8 & 16.2 & 11.5 & 2.9 & 14.4 \\
\hline Mexico ${ }^{24}$ & 2006 & $5-17$ & 57.1 & 18.6 & 9.5 & 28.1 & 20.3 & 8.7 & 29 \\
\hline South Africa ${ }^{4}$ & 2001-2004 & $6-13$ & 35.6 & 10.9 & 2.4 & 13.3 & 17.5 & 4.8 & 22.3 \\
\hline Sweden ${ }^{25}$ & $2000-2001$ & 10 & 36.5 & 14.2 & 2.8 & 17 & 16.5 & 3 & 19.5 \\
\hline Switzerland ${ }^{26}$ & 2007 & $6-13$ & 29.8 & & & 16.7 & & & 13.1 \\
\hline Taiwan $^{27}$ & 2001 & $6-18$ & 43.4 & 18.6 & 8.2 & 26.8 & 13 & 3.6 & 16.6 \\
\hline$U_{S A^{28}}$ & 2003-2004 & $6-17$ & 71.1 & 21.9 & 13.1 & 35.1 & 22.3 & 13.6 & 36 \\
\hline
\end{tabular}

Source: International Association for the Study of Obesity, September 2010. 0: obesity, OW: overweight. Please note that the provided data are limited by data availability. The above figures are not all based on nationally representative studies. 
because the children have less adult supervision in terms of the selection of food, both in terms of quality and quantity, as well as the nature of the physical activities in which they engage. ${ }^{29}$ International studies have found that approximately $20-50 \%$ of children who are obese before puberty will remain so in adulthood, and $50-70 \%$ of obese adolescents will retain this obesity in adulthood. ${ }^{32}$ The picture does not differ in South Africa. Earlier South African data have demonstrated that $10 \%$ of women are already obese between the ages of 15 and 24 years. ${ }^{33}$ Thus, adolescence is a crucial risk period for the development of persistent obesity. ${ }^{34}$ The co-morbidity profiling exerts an important toll on most societies. ${ }^{35}$ The observed trend between nutritional status and age, together with findings from previous research and South Africa data, suggest that it is important to give children a healthy start in life by instilling healthy eating habits in them and encouraging them to become more active.

This study found that overweight and obesity were more prevalent in the low SES group. It seems that the prevalence of overweight and obesity differs among countries depending on their level of development. Overweight prevalence is high among the poor in developed countries, and high among the rich in developing countries. ${ }^{17,35}$ Data from developing countries, other than South Africa, indicate that the determinants of overweight vary greatly across countries and cultural groups. ${ }^{6}$ Despite obesity being more prevalent in the high income groups, there is evidence that countries in economic transition, such as China, Brazil and South Africa, also have a general increase in the rate of obesity across all economic levels. ${ }^{31}$ Some studies have indicated that an increase in income usually results in the purchase of foods with more developed preparation and packaging and of a better quality, rather than in an increase in quantity. In the poorest population groups, diets tend to be characterised by a very high fat intake. Generally, more expensive vegetables, fruit and whole grains are eaten in lesser amounts. ${ }^{32}$

Trends were only observed for socio-economic indicators such as household income, source of income, parental employment and education. The only significant association that was found, the linking of working mothers with increased obesity in children, has also been found in other developing countries. ${ }^{36}$

Evidence on parental education and obesity in children indicates a direct relationship between a higher level of education in fathers (but a lower level of education in mothers), being associated with overweight or obesity in children, ${ }^{33}$ whereas a trend of increased prevalence of overweight and obesity in Stellenbosch primary schoolchildren was observed when mothers and fathers both had a low educational level.

In this study, households with two children had a significantly higher prevalence of overweight and obesity. Mother's age, marital circumstances and total household number did not seem to play a significant role. Corroborating this, a study that focused on transition and health during the urbanisation of South African children aged 10-15 years found that the prevalence of overweight was more apparent in smaller households. ${ }^{12} \mathrm{~A}$ UK-based survey found that only children, e.g. those without brothers or sisters, were more likely to become overweight. ${ }^{37}$
No significant association was found in the Stellenbosch study between breastfeeding practices as a protective factor in the prevention of childhood overweight or obesity in the second phase of the study. However, an observed trend was that most of the normalweight children were breastfed beyond six months of age. A possible protective effect of breastfeeding on the subsequent development of obesity is an infant feeding practice that has been a focus of interest in recent years. The literature indicates that in addition to the other benefits of breastfeeding, its initiation and duration may reduce the risk of later-life overweight and obesity. ${ }^{38,39}$

In the Stellenbosch study, it was found that eating meals together was not an indicator of childhood overweight or obesity, as was found in previous studies. ${ }^{15}$ Neither was any significant association found between set meals or where meals were eaten and the prevalence of overweight and obesity, except that a trend was observed whereby the children of mothers who carried out most of the cooking were more likely to be of a normal weight. It was encouraging to see that more than half of the Stellenbosch study population (normal weight, overweight and obese) had set mealtimes and that $50 \%$ ate most of their meals together as a family. European studies indicate that families with normal-weight children are more likely to eat together, than those with overweight or obese children. ${ }^{15}$

There is evidence that environmental factors that contribute to the development of obesity early in life include a shift in diet to more fast foods with a low-fibre, high-fat and calorie content. ${ }^{35}$

The Stellenbosch study supports previous findings, $32,35,40$ that overweight and obesity prevalence increases as screen time increases ${ }^{41}$ and participation in sport decreases. ${ }^{40}$ Modern society contributes to a further increase in sedentary activities because of advances in technology, discontinuation of physical activity in schools, as well as the security risk that the children are exposed to whenever they are away from home. Adequate facilities which allow children to safely engage in physical activity, both in schools and in the community, are lacking, and this contributes to this problem. ${ }^{29}$ The increase in physical activity is central to the management of weight problems in all age groups. Sedentary children require a very low dietary energy intake in order to control their weight. It is difficult to consume a diet that is adequate in minerals, vitamins and trace elements within such a restricted calorie intake. ${ }^{42}$

The indicated levels of overweight and obesity among Stellenbosch children in this study, coupled with the results from other South African research, are of concern in South Africa at present and in the future. By preventing or reducing the prevalence of childhood overweight and obesity, it may be possible to reduce the prevalence of adult obesity by between $7 \%$ and $13 \%{ }^{43}$

This study was limited by the poor response rate and limitations of the selected research instruments. Although there was a poor response rate of only $27 \%$ in the second phase of the study, this is consistent with response rates in other school-based studies. Time limitations around the school terms and holidays potentially affected the response rate. Furthermore, the poor response rate may also be 
attributed to children not giving the questionnaires to their parents, or parents not taking an interest in the information that was sent home from the school. As the questionnaire was self-administered by the caregivers, the literacy level of the caregiver who completed the questionnaire could have influenced the response rate, as well as the accuracy and completeness of the returned questionnaires. As dietary intake was measured using only one dietary assessment method, the results were not validated and provide only estimated intake, not absolute nutrient intakes. However, FFQ have been previously validated as a measure of dietary patterns. Therefore, it is not possible to generalise about the conclusions in this article. They should be considered to be preliminary findings and warrant further investigation.

\section{Conclusion and recommendations}

Although a lower prevalence rate of overweight and obesity was observed in this study than that in international and previous South African studies, it is important to note that South Africa is still in nutrition transition. Its prevalence rates are similar to those in developed countries a decade ago. As found in other studies, higher prevalence rates were observed in girls and among older children. This is of concern because the early onset of obesity continues into adulthood. In this study, SES factors that were found to be associated with overweight and obesity were poverty and low education levels, as found in other countries in economic transition. These result in poorer quality diets. The impact of working mothers further exasperates this. Mothers have less time for food preparation and increase the use of convenience foods, or exclude essential food groups, such as vegetables. In this study, the higher prevalence of overweight in smaller households was similar to that emerging in developed countries. Dietary patterns were not conclusive, but a trend was observed that breastfeeding was a possible protective factor. Also, the intake of some food followed the trend in which a higher fat and lower fibre intake was increased in families with overweight and obese children. Encouraging patterns, such as set mealtimes and eating together as a family, were observed, whereas increased screen time and decreased participation in sport were noted in overweight and obese children.

In the light of this evidence, preventative initiatives should proactively promote healthy eating behaviour and physical activity in children at an early age, and girls in particular. Involving families, day clinics, day care centres and schools in these initiatives is recommended. Eating behaviour strategies can include vegetable gardens at schools and day care centres, ensuring healthy lunch boxes at schools, making certain that tuck shops provide healthier food options, having "nutrition days" at schools or aftercare facilities to educate children and promote healthier food choices, and making sure that nutrition education is incorporated into the school curriculum.

Physical activity can be encouraged by involving parents to make time for the family by engaging in sports activities and other regular physical activities, such as playing games and going for walks and outings. Parents should also encourage children to perform general household chores to increase activity levels. Guided instructions and supervised practice by teachers, coaches and others who work with children, are important if children are to learn movement skills. It is very important to ensure that physical education classes are equally distributed across schools from different SES groups.

Dietitians and nutritionists can get involved at a local level by providing nutrition-related talks to schools and the public to encourage healthy eating and regular physical activity. Ideally, schools should be encouraged to take part in the Health Promoting Schools Initiative which incorporates many of these proposals.

On a national level, a childhood obesity-monitoring system would aid in identifying children who are at risk and tracking childhood obesity trends to guide evidence-based interventions to tackle this major health problem. Children should be weighed and measured at clinics and school level at timely intervals. This could then be used to calculate BMI for screening and epidemiological (overweight and obesity prevalence at a population level) purposes. Screening at individual level would identify children who are at risk of overweight and obesity, but can also serve as a tool with which to identify schools and areas that should be prioritised in terms of intervention. Screening must be incorporated into national policy, but can be implemented at a local level if teachers and health staff are trained correctly in terms of nutritional status assessment.

Different causes or associated factors play a role in childhood obesity in the various provinces and local communities in South Africa, because the population is diverse in terms of culture and sociodemographics. Therefore, replicating this study in different areas could provide insight into local causative or associative factors.

\section{References}

1. Controlling the global obesity epidemic. World Health Organization [homepage on the Internet.] c2011. Available from: http://www.who.int/nutrition/topics/obesity/en

2. International Obesity Task Force [homepage on the Internet] c2011. Available from: http://www.iotf.org/obesity

3. Strauss RS, Knight J. Influence of the home environment on the development of obesity in children. Pediatrics. 1999;103(6):e85.

4. Armstrong MEG, Lambert MI, Sharwood KA, Lambert EV. Obesity and overweight in South African primary school children: the Health of the Nation Study. S Afr Med J. 2006;96(5):439-444.

5. Kinra S, Nelder RP, GJ Lewendon. Deprivation and childhood obesity: a cross sectional study of 20973 children in Plymouth, United Kingdom. J Epidemiol Community Health. 2000;54(6):456-460.

6. Steyn NP, Labadarios MB, Mauder E, et al. The National Food Consumption Survey (NFCS): South Africa, 1999. Public Health Nutr. 2005;8(5):533-543.

7. Labadarios MB, Mauder E, MacIntryre U, et al. Secondary anthropometric data analysis of the national food consumption survey in South Africa: the double burden. Nutrition. 2005;21(1):4-13.

8. Reilly JJ, Armstrong J, Dorosty AR, et al. Early life risk factors for obesity in childhood: cohort study. Brit Med J. 2005;330(7504):1357.

9. Jinabhai CC Taylor M, Sullivan KR. Changing patterns of under- and over-nutrition in South African children - future risks of non-communicable diseases. Ann Trop Paediatr. 2005;25(1):3-15.

10. Juresa V, Kuzman M, Pavic Simetin I, et al. Prevention of overweight and obesity in childhood, a guideline for school health care [homepage on the Internet]. European Union for School and University Health and Medicine. c2007. Available from: http://www. eusuhm.org/bestanden/C00P\%20guideline\%20text.pdf

11. Mamabolo RL, Alberts M, Steyn NP, et al. Prevalence and determinants of stunting and overweight in 3-year-old black South African children residing in the Central Region of 
Limpopo Province, South Africa. Pub Health Nutr. 2005;8(5):501-508.

12. Kruger R, Kruger HS, MacIntyre UE. The determinants of overweight and obesity among 10- to 15-year-old schoolchildren in the North West Province, South Africa: the THUSA BANA (Transition and Health during Urbanisation of South Africans BANA, children) study. Pub Health Nutr. 2006;9(3):351-358.

13. Golan M. Influence of the home environment on the development and treatment of childhood obesity. Shanghai: Nestlé Nutrition Workshop: Obesity in childhood and adolescence; 2001.

14. Mchiza ZJ, Goedecke JH, Lambert EV. Intra-familial and ethnic effects on attitudinal and perceptual body image: a cohort of South African mother-daughter dyads. BMC Public Health. 2011;11:433.

15. Jefferson A. Breaking down barriers: examining health promoting behaviour in the family. Kellogg's Family Health Study 2005. Nutr Bull. 2006;31:60-64

16. Troiano F, Flegal K. Overweight children and adolescents: description, epidemiology and demographics. Pediatrics. 1998;101(3 Pt 2):497-504

17. Obesity in Europe. International Obesity Task Force with the European Childhood Obesity Group: Copenhagen: IOTF [homepage on the Internet]. c2007. Available from: http:// www.iaso.org/resources/aboutobesity/child-obesity

18. 2007 Australian National Children's Nutrition and Physical Activity Survey: main findings Australian Government, Australian Food and Grocery Council, Australian Government Dept of Agriculture, Fisheries and Forestry 2007 [homepage on the Internet]. c2008. Available from: http://www.health.gov.au/internet/main/publishing.nsf/content/66596E 8FC68FD1A3CA2574D50027DB86/\$File/childrens-nut-phys-survey.pdf

19. De Assis MAA, Rolland-Cachera MF, Grosseman S, et al. Obesity, overweight and thinness in schoolchildren of the city of Florianópolis, Southern Brazil. Eur J Clin Nutr 2005;59(9):1015-1021.

20. Kain J, Uauy R, Vio F, Albana C. Trends of overweight and obesity prevalence in Chilean children: comparism of three definitions. Eur J Clin Nutr. 2002;56(3):200-204.

21. Yanping L, Evert GS, Xiaogi $H$, et al. Obesity prevalence and time trend among youngsters in china, 1982 - 2002. Asia Pac J Clin Nutr. 2008;17(1):131-137.

22. Health Survey for England 2007: knowledge, attitudes and behaviour. National Health Service (NHS); 2008.

23. Japan over the last 25 years from the National Nutrition Survey. Obes Res 2004;12(2):205-214.

24. Encuesta nacional de salud y nutricion 2006 [homepage on the Internet]. c2007. Available from: $h t t p: / / w w w . i n s p . m x / e n s a n u t / e n s a n u t 2006 . p d f$

25. Mårild S, Bondestam M, Bergström R, et al. Prevalence trends of obesity and overweight among 10-year-old children in western Sweden and relationship with parental body mass index. Acta Paediatr. 2004;93(3):1588-1595.

26. Aeberli I, Amman RS, Knabenhans M, et al. Decrease in the prevalence of paediatric adiposity in Switzerland from 2002 to 2007. Public Health Nutr. 2010;13(6):806-811.

27. Chen LJ, Fox KR, Haase A,Wang JM. Obesity, fitness and health in Taiwanese children and adolescents. Eur J Clin Nutr. 2006:60(12):1367-1375
28. Lobstein T, Jackson-Leach R. Child overweight and obesity in the USA: prevalence rates according to IOTF definitions. Int J Pediatr Obes. 2007;2(1):62-64.

29. Cruz VA, Hisa QZT, Imson MG, Mang-usan DA. Obesity in school-aged children: prevalence and causes. University of the Cordilleras, Philippines. 2009;1(4):109-126 [homepage on the Internet]. Available from: http://www.eisrjc.com/documents/Obesity _ In_School-Aged_Children_1325667639.pdf

30. Reddy SP, Panday S, Swart D, et al. Umthenthe Uhlaba Usamila: The South African Youth Risk Behaviour Survey 2002. Cape Town: South African Medical Research Council; 2003 [homepage on the Internet]. Available from: http://www.mrc.ac.za/healthpromotion/ YRBSpart1.pdf

31. Monyeki KD, van Lenthe FJ, Steyn NP. Obesity: does it occur in African children in a rural community in South Africa? Int J Epidemiol. 1999;28(2):287-292.

32. De Lauzen B, Charles MA. Childhood obesity: influences of socio-economic factors Objectif Nutrition [homepage on the Internet]. 2004. c2008. Available from: http://www. danoneinstitute.org/objective_nutrition_newsletter/on73.php

33. Puone T, Steyn K, Bradshaw D, et al. Obesity in South Africa: The South African Demographic and Health Survey. Obes Res. 2002;10(10):1038-1048.

34. Dietz WH. Health consequences of obesity in youth: childhood predictors of adult obesity. Pediatrics. 1998;101(3 Pt 2):518-525

35. Van der Merwe MT. Childhood obesity. S Afr Fam Pract. 2004;46(6):16-19.

36. Anderson PM, Butcher KF, Levine PB. Maternal employment and overweight children. J Health Econ. 2003;23(3):477-504

37. Sullivan A. The Millennium Cohort Study. Third survey: a user's guide to initial findings. Centre for Longitudinal Studies, Institute of Education University of London. 2009 [homepage on the Internet]. 2009. c2011. Available from: http://eprints.ioe. ac.uk/5931/1/MCS_3_Descriptive_Report_0ct_2008.pdf

38. Arenz S, Ruckerl R, Koletzko B, von Kries R. Breastfeeding and childhood obesity: a systemic review. Int J Obes Relat Metab Disord. 2004;28(10):1247-1256.

39. Horta B BR, Martines J, Victora C. Evidence on the long-term effects of breastfeeding: systemic reviews and meta-analysis. Geneva: World Health Organization 2007 [homepage on the Internet]. Available from: http://whqlibdoc.who.int/ publications/2007/9789241595230_eng.pdf

40. Kimani-Murage EW, Kahn K, Pettifor JM, et al. The prevalence of stunting, overweight and obesity, and metabolic disease risk in rural South African children. BMC Public Health. 2010;10:158.

41. Anderson RE, Crespo CJ, Bartlett SJ, et al. Relationship of physical activity and television watching with body weight and level of fatness among children: results from the Third National Health and Nutrition Examination Survey. JAMA. 1998;279(12):938-942.

42. Lawson M. Toddler nutrition: what needs to be done. Journal Family Health Care. 2005;15(4):99-100.

43. Venn AJ, Thomson RJ, Schmidt MD, et al. Overweight and obesity from childhood to adulthood: a follow-up of participants in the 1985 Australian Schools Health and Fitness Survey. Med J Aust. 2007:186(9):458-460. 